\title{
J
}

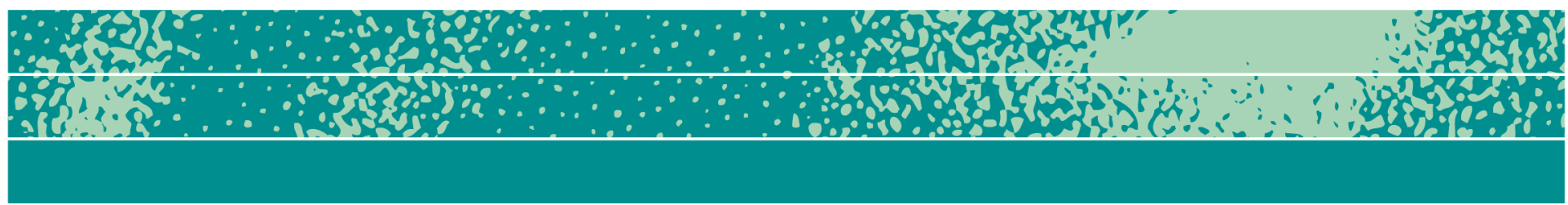

\section{Shifting Cases: Advancing a New Artifact for Entrepreneurial Education}

\author{
Marlo Rencher
}

\begin{abstract}
Entrepreneurship, as applied here, involves helping students develop an entrepreneurial mindset by working in a university-supported startup that lacks the artificiality of a simulation or the safety net of heavy financial subsidization. This article chronicles an organizational-wide change at a private Midwestern university and the development of a new "artifact" - the dynamic case study-to complement a new approach to business and entrepreneurial education. After reviewing the function of case studies in a teaching and research context, I consider this new kind of case study as a boundary object and means for making sense of early stage entrepreneurial activity.
\end{abstract} JBA 8(2): 211-227 Autumn 2019

\section{Key words}

entrepreneurship, case study, education, boundary object, organizationwide change

\section{Transformation at a Small Business University}

As part of the leadership team of Cleary University, a small, private, nonprofit business-focused school, I was part of a transformational 
process that represented a radical change in the institution's approach to education. The transformation was precipitated by a clear need to offer an educational program that was markedly different. One quote in particular by Michael Crow, President of Arizona State University, guided our actions and inspired us to diverge from the educational approach that had defined us for so long: "By establishing new criteria for success, we are choosing not to participate in a race that has already been lost" (Crow and Dabars 2015). The transformational process included revamping the entire curriculum and rethinking the educational experience. Precipitated by a change in leadership after 26 years with the same president, the process also required the university to reconsider itself. After years of financial floundering, the university needed to face some hard truths about its survival.

The early part of the twenty-first century has not seen much growth for small private colleges and universities. The number of private, nonprofit institutions fell by 33 from 1,909 to 1,876 (1.7 percent) from 2015-16 to 2016-17 (Lederman 2017).

The nationwide number of high school graduates is declining and will continue to decline in both public and private schools through the 2029-2030 school year. The decline is having a particularly negative impact in the Midwest and Northeastern U.S. (Marcus 2017). The 20162017 school year saw the sharpest decline, with 81,000 fewer high school graduates nationwide. Along with the decrease in students, many colleges struggle to sustain themselves on less net income.

Small private, nonprofit colleges and universities this year gave back, in the form of financial aid, an average of 51 cents of every dollar they collected from tuition. That's up from an average of 38 cents a decade ago - good news for students and their families, but a dangerous trend for colleges whose annual increases in revenue are failing even to keep pace with inflation (Marcus 2017).

Given this environment, offering an undifferentiated educational experience is not sustainable. Private colleges across the nation like Burlington College in Vermont, Grace University in Omaha, and St. Gregory's University in Oklahoma are closing. Marygrove College in Michigan discontinued its undergraduate programs after its fall 2017 semester. When demand is low and supply is high, a school must provide a remarkable product offering to survive and ultimately thrive.

Specialty colleges like Minerva in headquartered in California, Hampshire College in Massachusetts, College for Creative Studies in Michigan, and Unity College in Maine have chosen distinctive niches that they can promote. They have chosen to be great at something specific rather than being good at being average. To ensure that Cleary University would be sustainable in the long term, we made the same choice. This 
choice was inherently risky, but we felt that doing nothing distinctive carried even more risk.

In this article, I describe a change process at U.S.-based Cleary University in Michigan, where I served as the vice president of innovation, entrepreneurship and diversity until December 2018. Founded in 1883, the university is now reinventing itself in response to the challenges faced by the educational sector as a whole. Cleary is still in the early stages of that transformation.

The change process has required a rethinking of how we deliver education. As a result, we have adopted a number of new tools and techniques that serve as material markers of our transformation. One of these tools is a collaborative online space that will have distinct repositories for each of the businesses that are created. While we are at the very beginnings of creating that tool, there are theoretical implications of this approach that are relevant for business anthropologists and instructive for educators and entrepreneurs.

\section{Literature Review}

\section{Case Study Definitions and Objectives}

Case studies have multiple purposes in a business education context. Harvard originated the business case in the 1920s as a novel methodology developed to complement another emergent educational concept, the Master of Business Administration degree (Normand 2017). The business case format helps to organize disparate facts in a way that facilitates analysis. Typically, the facts of the case are delivered in an engaging, narrative format. There are usually no clear answers to a business case. Business cases were innovative because they approximated the ambiguity of real life and told a compelling, realistic story. The case study method is the dominant teaching methodology in business schools today, nearly 100 years later.

Case studies are also a research methodology, a methodology for which there is no standard definition and for which there are multiple aims. Schramm focused on a simple view of the aim of case studies: to illuminate a decision or set of decisions-why they were taken, how they were implemented, and with what result (Schramm 1971).

Yin (2013: 18) provides a more detailed approach that infers a holistic, theoretically-driven and comprehensive approach. He proposes a twofold definition and takes a definite stand in using case studies to test theoretical propositions rather than build them:

1. A case study is an empirical inquiry that

a. Investigates a contemporary phenomenon in depth and within its real-life context, especially when 
b. The boundaries between phenomenon and context are not clearly evident.

2. The case study inquiry

a. Copes with the technically distinctive situation in which there will be many more variables of interest than data points, and as one result

b. Relies on multiple sources of evidence, with data needing to converge in a triangulating fashion, and as another result

c. Benefits from the prior development of theoretical propositions to guide data collection and analysis.

Eisenhardt (1989) advocated for case studies as a means for theory-building, providing a roadmap for doing so. Her steps can be summarized as follows:

1) getting started (defining research question),

2) selecting cases (defined population, but no defined hypothesis or theory to test),

3) crafting instruments and protocols (multiple, mixed methods, multiple investigators),

4) entering the field (overlap collection and analysis, flexible, opportunistic data collection),

5) analyzing data (within-case analysis and cross-case pattern search using divergent techniques),

6) shaping hypotheses (iterative tabulation of evidence for each construct, replication logic, search for "why"),

7) enfolding literature (comparison with conflicting and similar literature),

8) reaching closure (theoretical saturation when possible).

Dul and Hak (2007: 30) make a distinction between practiceoriented and theory-oriented case study research:

We define theory-oriented research as research that is aimed at contributing to the development of theory. The academic community is the primary user of research findings. We define practice-oriented research as research that is aimed at contributing to the knowledge of specific practitioners responsible for a specific practice. A practice is the real life situation for which a practitioner has either a formal or an informal responsibility, and in which he acts or must act. Members of the business community are the primary users of these research outcomes.

Dul and Hak further specify that the value of practice-oriented research is to solve problems through a process called the intervention 
cycle. The intervention cycle depicts problem solving as an iterative process consisting of five specific phases:

1) problem finding: identification and definition of a problem;

2) problem diagnosis: finding out why a problem exists (causes);

3) design of intervention: designing an intervention (based on a diagnosis) that should (help to) solve the problem;

4) implementation: implementing the intervention that has been designed;

5) evaluation: ascertaining whether the aims of the intervention have been achieved and whether (or to what degree) the problem has been solved. They indicate that the problem-solving process should be undertaken in the order specified (Dul and Hak 2007: $\underline{54)}$.

\section{Boundary Objects}

The intersections of different viewpoints inherent in the collaboration spaces and the use of the space as an object of intense study call to mind the notion of boundary objects. Introduced by Starr and Griesemer (1989: 393), the concept of boundary objects is especially relevant for the collaborative spaces because of their use by multiple parties with different viewpoints in making sense of the object of study from their own perspective.

[Boundary objects are] an analytic concept of those scientific objects which both inhabit several intersecting social worlds... and satisfy the informational requirements of each of them. Boundary objects are objects which are both plastic enough to adapt to local needs and the constraints of the several parties employing them, yet robust enough to maintain a common identity across sites. They are weakly structured in common use, and become strongly structured in individual site use. These objects may be abstract or concrete. They have different meanings in different social worlds but their structure is common enough to more than one world to make them recognizable, a means of translation. The creation and management of boundary objects is a key process in developing and maintaining coherence across intersecting social worlds.

Starr and Griesemer identified repositories as being one of four specific types of boundary objects. The others are ideal type (a generic roadmap, description or diagram used for setting a common course or direction), coincident boundaries (common objects with the same boundaries but different internal contents), and standardized forms. The heterogeneity and complexity of boundary objects adds to their utility as 
a robust explanatory model. The process of building a business requires structuring and developing business planning artifacts.

An important feature of boundary objects is their multiplicity. They exist in different worlds and translate meaning between them. Thus, boundary objects have clear relevance for teaching and learning and organizational change as a "knowledge integration mechanism" (Trompette and Vinck 2009). The interpretive flexibility that Trompette and Vinck describe is particularly useful for entrepreneurship, where the experience is particularly elusive and difficult to capture. Inherent in the multiplicity of boundary objects is the opportunity for them to serve as coordinating objects, enabling collaboration and facilitating the achievement of common objectives. Gluesing (2018: 34) explains this feature:

While boundary objects have different meanings in the different worlds of heterogeneous actors, different groups can recognize those meanings because they are still sufficiently structured around a common goal, e.g. to improve the functioning of a global team or to achieve a shared business objective. The notion of boundary objects is used to describe how people maintain their differences and their cooperation and how they coordinate in space and time. Thus people from different social worlds are able to negotiate differences and establish agreement on their respective points of view.

Another highly relevant feature of boundary objects is their persistence over time. Objects such as social media timelines and journaled diaries capture successive glimpses of their subjects that require expression over time in order to be fully articulated. These objects can provide insight about the change and growth of their object of attention. They also make plain the inherent sociality involved in business creation. Such data about entrepreneurship and its attendant activities, particularly in the early stages of a startup, could be a source of rich insight.

\section{Activity and Entrepreneurship}

Businesses are created and sustained through activity. Activity theory is a useful framework for understanding the sociocultural context of activity and artifacts as they relate to entrepreneurship. Activity theory takes the object-oriented, artifact-mediated collective activity system as its unit of analysis, bridging the gulf between the subject (an individual or group) and society (Engeström 2014). Activity theory's expansive cycle-in which internalization (the intellectual aspect of activity) and externalization (the embodied aspect of activity) processes are dialectically enmeshed to produce new social structures and cultural meaning - is a useful way of thinking about the process of organizing a 
startup business (Rencher 2012). As Garcia-Lorenzo et al. (2017: 373) noted,

Entrepreneurship is therefore about the emergence of creative organizing actions, yet current research tends to focus on examining its fixed qualities, thereby rendering invisible what goes on during 'in-between' entrepreneuring processes (Cardon, Wincent, Singh \& Drnovsek, 2009; Hjorth, 2005). It is in this 'betwixt and between' (Turner, 1967), however, where we can better observe how creative organizing actions, play, and improvisational entrepreneurial processes occur.

My research on Detroit entrepreneurial communities revealed four types of entrepreneurial activity systems: 1) organizing, 2) networking, 3) pitching and 4) nurturing. Networking and pitching are emic activity categories. Organizing and nurturing are etic activity categories. The inclusion of both perspectives offers a holistic approach. As understood through the lens of activity theory, these entrepreneurial activities involve a constant interplay and exchange among objects, actors, and society (Rencher 2012).

\section{Preparing for a University-Wide Process Change}

The Cleary Mind ${ }^{T M}$ and its Attributes

Leadership's response to the challenges facing the university was dubbed The Cleary Mind ${ }^{\mathrm{TM}}$ Initiative. The Cleary Mind was defined as the educational advantage achieved through successful inculcation of eight attributes consistently over the course of undergraduate education or graduate education.

The eight attributes of The Cleary Mind are: 1. Critical Thinking, 2. Problem Solving, 3. Creative Thinking, 4. Communications, 5. Persuasion, 6. Entrepreneurship (Entrepreneurial Mindset), 7. Leadership, and 8. Ethics (See Figure 1). Ultimately, the foundation of the university's transformation rests on these eight attributes. They are the basis for our curriculum redesign and assessment metrics and embedded in all change efforts. 


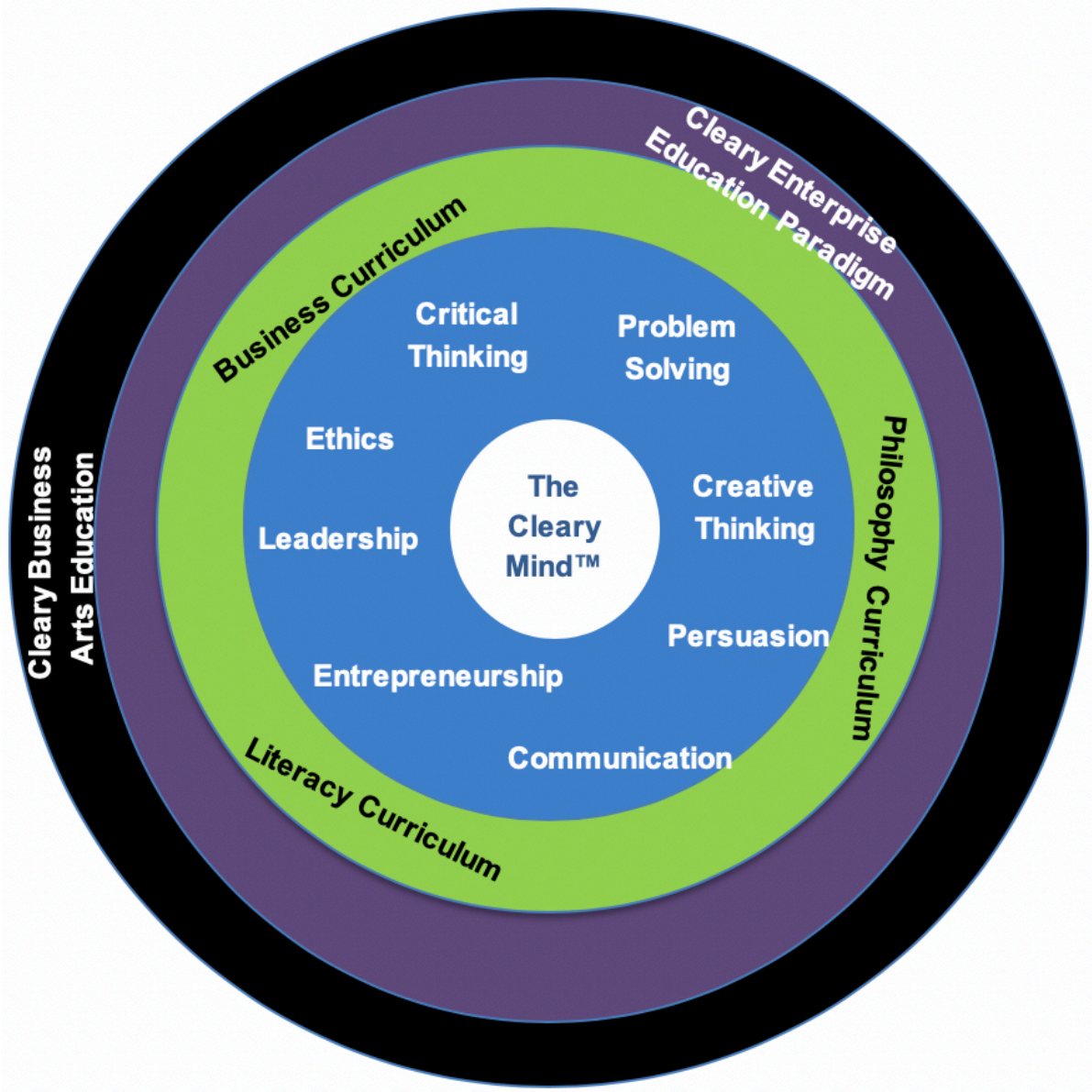

Figure 1. The Cleary Mind ${ }^{\mathrm{TM}}$

Figure 1 is a crystallization of our thinking about The Cleary Mind initiative. It includes the eight attributes at the core of the initiative, wrapped up in a curriculum that balances business, philosophy and literacy. The attributes were developed based on a product/customer reorientation that occurred early in the transformational process. In 20 , we saw the student as the customer and sold a credentials to that student. We shifted to prioritize employers and parents as the customers. We sold prepared graduates. That shift led us to operationalize "prepared" from the point of view of employers. We discussed the gaps with community stakeholders and industry advisors. We developed the attributes based on those discussions. We learned that job candidates with this combination of attributes are rare and valuable. We sampled business publications. Table 1 shows the frequency with which the eight attributes are identified as being desirable in a small sample of business publications. Entrepreneurship was not mentioned frequently-we believed that most employers think of entrepreneurship as an attribute that is inconsistent with formal employment. Entrepreneurs are commonly defined as people who operate their own enterprises, and not people who work within a company in which they have no ownership stake. 
Table 1. Frequency of Eight Attributes in Sample of Business Publications

\begin{tabular}{|c|c|c|c|c|c|c|c|c|}
\hline Article & $\begin{array}{c}\text { Critical } \\
\text { Thinking }\end{array}$ & $\begin{array}{c}\text { Problem } \\
\text { Solving }\end{array}$ & $\begin{array}{l}\text { Creative } \\
\text { Thinking }\end{array}$ & $\begin{array}{l}\text { Communi } \\
\text { cations }\end{array}$ & $\begin{array}{l}\text { Persua } \\
\text { sion }\end{array}$ & $\begin{array}{l}\text { Entrepre } \\
\text { neurship }\end{array}$ & $\begin{array}{l}\text { Leader } \\
\text { ship }\end{array}$ & Ethics \\
\hline $\begin{array}{l}\text { The Top } 10 \text { Traits } \\
\text { Employers Want } \\
\text { in Business School } \\
\text { Graduates, } \\
\text { GoodCall }\end{array}$ & & & & & & & $\mathbf{X}$ & $\mathbf{X}$ \\
\hline $\begin{array}{l}\text { College vs. } \\
\text { Business Training: } \\
\text { What Do } \\
\text { Employers Want? } \\
\text { Wharton, } \\
\text { University of } \\
\text { Pennsylvania }\end{array}$ & X & $X$ & & $X$ & $X$ & & $\mathbf{X}$ & \\
\hline $\begin{array}{l}\text { Eight Essential } \\
\text { Skills Every } \\
\text { Employer Looks } \\
\text { for in Recent } \\
\text { Graduates, Inc. }\end{array}$ & & & $\mathbf{X}$ & $\mathbf{X}$ & $\mathbf{X}$ & & $\mathbf{X}$ & $\mathbf{X}$ \\
\hline $\begin{array}{l}\text { What Employers } \\
\text { Really Look for in } \\
\text { Recent College } \\
\text { Graduates, USA } \\
\text { Today }\end{array}$ & & & & & & & $\mathbf{X}$ & \\
\hline $\begin{array}{l}\text { What Employers } \\
\text { Are Looking for } \\
\text { When Hiring } \\
\text { Recent College } \\
\text { Grads, Forbes }\end{array}$ & $X$ & $\mathbf{X}$ & $\mathbf{X}$ & $X$ & $\mathbf{X}$ & $\mathbf{X}$ & & \\
\hline $\begin{array}{l}\text { New College } \\
\text { Grads: Who } \\
\text { Employers Want } \\
\text { to Hire, CBS News } \\
\text { MoneyWatch }\end{array}$ & $X$ & $\mathbf{X}$ & & $X$ & $\mathbf{X}$ & & & $\mathbf{X}$ \\
\hline $\begin{array}{l}\text { What Employers } \\
\text { Want from MBAs } \\
\text { This Year, Poets \& } \\
\text { Quants }\end{array}$ & X & $\mathbf{X}$ & & & & & & \\
\hline $\begin{array}{l}\text { The } 10 \text { Skills } \\
\text { Employers Most } \\
\text { Want in } 2015 \\
\text { Graduates, Forbes }\end{array}$ & $X$ & $\mathbf{X}$ & & $X$ & $\mathbf{X}$ & & & \\
\hline $\begin{array}{l}\text { What Employers } \\
\text { Want, Graduate } \\
\text { Opportunities.com }\end{array}$ & & & & $\mathbf{X}$ & $\mathbf{X}$ & & $\mathbf{X}$ & \\
\hline
\end{tabular}




\section{The Cleary Business Arts ${ }^{T M}$ Education}

Ultimately, these eight attributes were integrated into the educational experience through a redesigned curriculum, The Cleary Business Arts ${ }^{\mathrm{TM}}$ Curriculum. The curriculum integrates philosophy and literacy (reading, writing, cultural, and technological literacy) into a business core. Students participate in four one-credit university courses that help them to develop their entrepreneurial mindset. We focused on building the entrepreneurial mindset because we believed that it was necessary to create prepared and proactive graduates. The courses are formatted as four, half-day workshops. The topics are Ideation and Innovation, Creating Compelling Value, Structuring the Future (on business planning), and The Persuasive Pitch.

The Cleary Enterprise Education ${ }^{\mathrm{TM}}$ Paradigm (EEP) is the experiential integration of the eight attributes that complements the theory (See Figure 2). EEPs are university-based, student-managed, forprofit corporations integrated into the educational framework. Students participate in the EEP as staff and management of corporations.

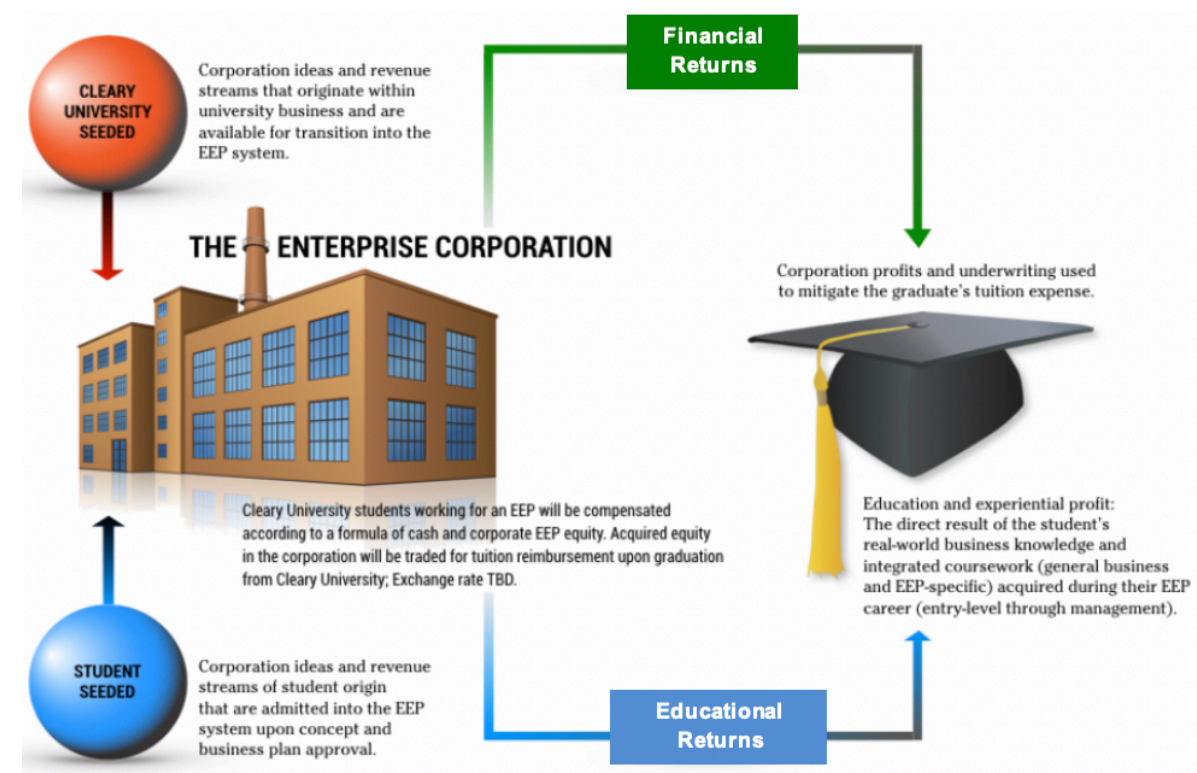

Figure 2. The Cleary Enterprise Education ${ }^{\mathrm{TM}}$ Paradigm

Each EEP must achieve certain milestones to demonstrate satisfactory progress as defined by the university (See Figure 3). The business idea must be submitted first via a standardized form. The form requires an explanation of the business concept, customers, competitors, and the benefits of a collaboration with Cleary University. 


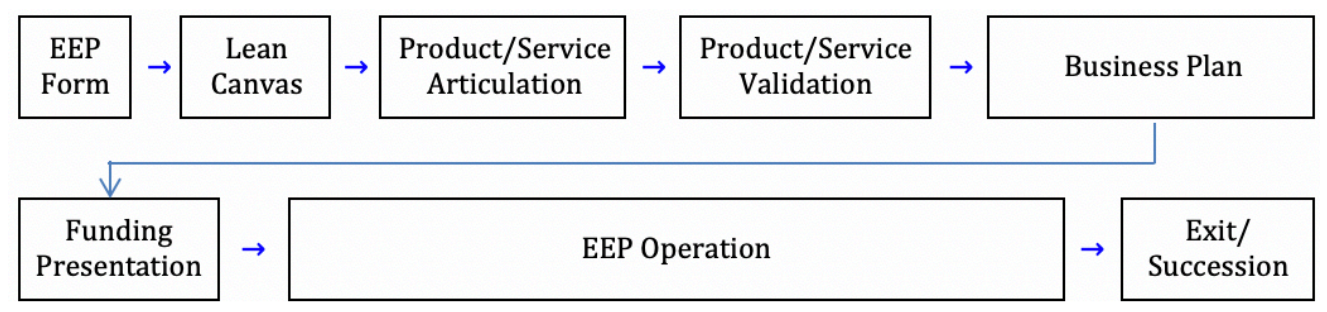

Figure 3. The Cleary Enterprise Education ${ }^{\mathrm{TM}}$ Paradigm Business Development Process

Next, the founding team must complete a "Lean Canvas" for the business idea. The Lean Canvas is a one-page planning document with spaces to indicate key assumptions. It was developed by Ash Maurya as an evolution of the Business Model Canvas (Osterwalder and Pigneur 2013), a popular business planning tool. With the Lean Canvas, students identify and articulate key elements of their business idea such as Problem (the top three problems that their business is organized to solve), Existing Alternatives (ways businesses solve those problems today), and Unique Value Proposition (the clear, compelling message that states why the business idea is different and worth paying attention to)(Maurya 2012).

The Lean Canvas helps its users confront their assumptions about their business ideas. It is a useful tool to guide testing and revising those assumptions. Testing the assumptions involves developing prototypes and experiments that approximate the product or service being examined. As the assumptions are tested, the business moves from assumptions and experiments to a more stable sense of what the business idea is. The original idea of the founder rarely emerges intact from interaction with customers. Informed by their customer tests, the founders must articulate what product or service they will validate and plan.

The next step in the process is to validate the business concept fully. Students must ensure that the concept is something people want enough to pay for. They must ensure that it is operationally, technically, and legally feasible. The students create a business plan and develop a pitch for resources--whether or not they are looking for funding. Then, the founders and managers, who are these students, focus on operating and growing the company. They must exit the company upon graduation, so the managers must create a succession plan as part of their business plan.

The students working in the businesses are paid. They also earn a bonus that is applied against the cost of accumulated tuition upon graduation. The businesses are not protected against failure. If a business is not viable, the university does not subsidize it; employees and managers seek employment in another EEP business. These steps are 
required both for those companies initiated by the students and companies initiated by the university. Students in each EEP are assisted by a body of industry-specific mentors. An advisory board has oversight responsibility of all EEP businesses.

The students, mentors, advisory board, investors and stakeholders collaborate to create Dynamic Case Studies, each serving as a repository for each EEP. As each company is built, validated, and operated, participants connected to the business can record documentation, experiences, thoughts, intellectual property, procedures, and related social media posts on a virtual space. These Dynamic Case Studies ultimately will serve as dynamic, thickly-described, longitudinal case studies. They will exist in sharp contrast to the static case studies typical in most business educational experiences. It is important to note that these Dynamic Case Studies have been planned but not yet implemented.

\section{The Dynamic Case Study}

Dynamic Case Studies are designed to be practice-oriented research whose objective is to improve the knowledge of the students working in the business. The Dynamic Case Studies have the additional function of facilitating the sensemaking and rationalization process that emergent organizations undergo. This sensemaking and rationalization happen not just for workers within the organization, but also for other students who are not working in the business but who are learning from the issues surfaced during the course of business development. The first few years are exploratory practice-oriented research. I anticipate that directions for hypothesis testing will emerge over time.

The people involved with the individual EEPs document their dayto-day activities as well as any problems or issues that arise; they use the intervention cycle specified by Dul and Hak (See Figure 4). Where possible, staff, mentors and students not directly involved in the businesses assist those who are directly involved to move through the intervention cycle. These issues serve as the basis for course projects in The Cleary Business Arts ${ }^{\mathrm{TM}}$ Curriculum. Students studying the issues provide their feedback into the Dynamic Case Studies. This feedback helps to provide an overlap between data collection and analysis recommended by Eisenhardt and keep the data collection fresh and opportunistic. I expect that the Dynamic Case Studies will evolve and change over time to accommodate new insights and sources of inquiry. 


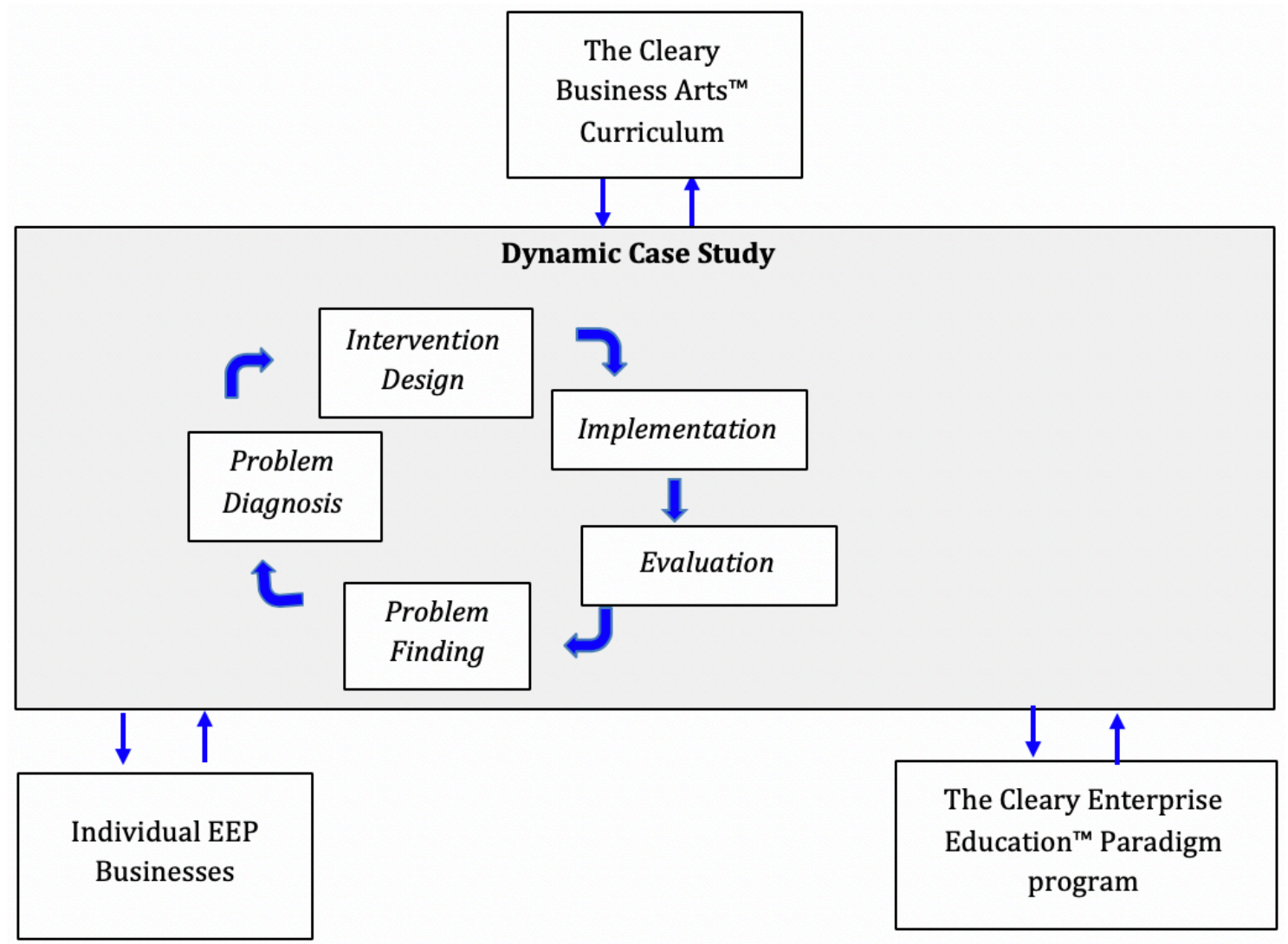

Figure 4. The Cleary Enterprise Education ${ }^{\mathrm{TM}}$ Paradigm Dynamic Case Study Information Flow (including Intervention Cycle)

Ultimately, the courses within the curriculum will evolve to make the best use of Dynamic Case Studies. The director with oversight of the program will also have access to the Dynamic Case Studies and will use best practices between businesses to assist where needed.

\section{Discussion}

We have conceived of Dynamic Case Studies as boundary objects that are a useful frame for making sense of the activity involved in building a business from multiple perspectives - from the entrepreneurs and managers building the businesses, to the students studying their activity, to the educators teaching the students, to the institution articulating a novel kind of educational experience. Boundary objects can facilitate creation and herald "the new", providing context and guidance for activity.

Organizing is an activity system involving the transmission and adoption of rules and standards. In the case of the EEP businesses, the activities related to the validated business planning process can be categorized as organizing. Networking, discovery-oriented resource gathering, has two primary aspects: 1 ) building a network, creating 
meaningful connections with people for the purpose of gaining resources and 2) activating or mobilizing a network to capture those resources. Networking happens in the EEP development process through sharing of problems and solutions with students, mentors and other stakeholders. This activity is mediated by the Dynamic Case Study. Pitching activities are connected with the physical representation of a startup through the entrepreneur or their artifacts, including boundary objects such as the Dynamic Case Study, the Lean Canvas, and the business plan. Nurturing activities generate faith and confidence for the entrepreneur. We believe that using Dynamic Case Studies to document day-to-day activities will create an environment to facilitate a sense of community and shared experience. We will encourage and contribute to inspirational sayings and motivational messages that instill confidence and faith in the students working on the EEP businesses.

Dynamic Case Studies capture each of these types of activities and place them in a temporal context. While some of these activities are public, most entrepreneurial activities are not public and not particularly visible for study or reflection. Startups evolve and change all the time, particularly in their earliest stages. Being able to see the pivots and the shifts of the founders over time would provide more directional data. Their process of sense- and meaning-making would be more visible, adding context to key performance indicators such as revenue, profitability, and production output. More research about the day-to-day activities and actions of entrepreneurs would provide much needed illumination about the human side of the business building process. Entrepreneurship is found in the activities, in the movement and creation of a business, as stated by Anderson (2005: 7):

Entrepreneurship is a process of creating, not a thing in itself. If pushed to reify it, it may be said to be a condition, a state of economic creativeness. For entrepreneurs, our habitual reification is doubly misleading. Being an entrepreneur is an ephemeral event, one can only entreprende temporarily, when actually creating or changing a business; anything after this crystallisation event is not entrepreneurship. Of course when we talk of entrepreneurship we usually mean the process of becoming, thinking, planning, conspiring, doing the things which may lead to entrepreneurship. In consequence it seems reasonable to claim that entrepreneurship, as we use the term, is the performance of the process of becoming. But becoming is not fixed in time or space; the aspiration may have germinated in childhood; the idea may have resulted from a fleeting thought and gathering the physical, mental resources and courage may have taken half a lifetime. To appreciate entrepreneurship, in the sense I used earlier, we need to acclaim or criticise it as a processual performance. So entrepreneurship as a performance of becoming 
is transitive, transitory and ephemeral. It fits, and may even fill, the liminal spaces between the here and then. Indeed, the literal translation of entrepreneurship - "going between"- proposes such a boundary spanning activity.

\section{Future Development and Concluding Thoughts}

The implementation of The Cleary Mind was in its nascent stages as I left the university. Upon reflection, there are several areas that I have identified as deserving more development and thought. From a theoretical perspective, we want to know more about ritual activity as it relates to entrepreneurial behavior. How does activity go from random to ritual? How does that process relate to the development and stability of a new enterprise? We also want to know more about the performance of entrepreneurship, particularly as it relates to how these students characterize their businesses, their activities and themselves in a digitally-mediated environment. A more practical concern is determining the best way to utilize class teams to help students solve problems. We need to know how to create a safe space for students to engage in nurturing activities in the Dynamic Case Study. We must balance privacy protection with appropriate access.

We must recognize education and entrepreneurship as human endeavors. As anthropologists, we possess a unique perspective about what gives meaning to our lives. We prod and poke at that which is anchored in culture, analyzing and problematizing those artifacts and rituals that make up "the way we do things around here". It is with that inquisitive spirit that I explored and participated in the development of an artifact which will serve as the university's platform for teaching, learning, and researching key business topics. It is my hope that more anthropologists contribute to the development of new innovations as well as study them.

\section{References}

Anderson, A. 2005. Enacted Metaphor: The Theatricality of the Entrepreneurial Process, International Small Business Journal 23 (6): 587603. https://doi.org/10.1177/0266242605057654

Crow, M. and W. Dabars. 2015. Designing the New American University. Baltimore, MD: Johns Hopkins University Press.

Dul, J., and T. Hak. 2007. Case Study Methodology in Business Research. New York, NY: Routledge.

Eisenhardt, K. 1989. Building Theories from Case Study Research, Academy of Management Review 14 (4): 532-550. https://doi.org/10.5465/amr.1989.4308385 
Engeström, Y. 2014. Learning by Expanding: An Activity-Theoretical Approach to Developmental Research. New York, NY: Cambridge University Press. https://doi.org/10.1017/CB09781139814744

Garcia-Lorenzo, L., P. Donnelly, L. Sell-Trujillo, and J. Miguel Imas. 2017. Liminal Entrepreneuring: The Creative Practices of Nascent Necessity Entrepreneurs, Organization Studies 39 (2-3): 373-395. https://doi.org/10.1177/0170840617727778

Gluesing, J. 2018. Using Boundary Objects to Facilitate Culture Change and Integrate a Global Top Management Team, Journal of Business Anthropology 7 (1): 32-50. https://doi.org/10.22439/iba.v7i1.5491

Lederman, D. 2017. The Culling of Higher Ed Begins, Inside Higher Ed. July 19. https://www.insidehighered.com/news/2017/07/19/numbercolleges-and-universities-drops-sharply-amid-economic-turmoil.

Marcus, J. 2017. Universities and Colleges Struggle to Stem Big Drops in Enrollment. The Hechinger Report. June 29.

https://hechingerreport.org/universities-colleges-struggle-stem-bigdrops-enrollment/.

Maurya, A. 2012. Running Lean: Iterate from Plan A to a Plan That Works. Sebastopol, CA: O’Reilly Media, Inc.

Normand, Y. 2017. The History of the Case Study at Harvard Business School. HBX Business Blog. February 28.

https://hbx.hbs.edu/blog/post/the-history-of-the-case-study-at-harvardbusiness-school.

Osterwalder, A., and Y. Pigneur. 2013. Business Model Generation: A Handbook for Visionaries, Game Changers, and Challengers. Hoboken, NJ: John Wiley \& Sons.

Rencher, M. 2012. Crossing the Valley of Death: A Multi-Sited, Multi-Level Ethnographic Study of Growth Startups and Entrepreneurial Communities in Post-Industrial Detroit. Detroit, MI: Wayne State University.

Schramm, W. 1971. Notes on Case Studies of Instructional Media Projects. Stanford, CA: Stanford University, California Institute for Communication Research.

Star, S., and J. Griesemer. 1989. Institutional Ecology, Translations and Boundary Objects: Amateurs and Professionals in Berkeley's Museum of Vertebrate Zoology, 1907-39, Social Studies of Science 19 (3): 387-420. https://doi.org/10.1177/030631289019003001

Trompette, P., and D. Vinck. 2009. Revisiting the Notion of Boundary Object, Revue d'anthropologie des connaissances 3(1): 3-25.

Yin, R. 2013. Case Study Research: Design and Methods. Thousand Oaks, CA: SAGE Publications. 
Marlo Rencher, Ph.D., is an entrepreneur, anthropologist, and educator with over two decades of experience in startup and small business development. She has worked with startup founders in entrepreneurial incubators, accelerators, university programs, and development agencies. She is currently director of technology-based programs at TechTown, an entrepreneurial hub based in Detroit. She previously served as vice president of innovation, entrepreneurship and diversity at Cleary University, a nonprofit business institution headquartered in southeastern Michigan. A Michigan State University graduate with a BA in marketing, Rencher also has an MBA from the Ross Business School at the University of Michigan, and a Ph.D. in business anthropology from Wayne State University. Her research interests exist at the intersection of entrepreneurship, design, technology and culture. Rencher has founded or co-founded five tech companies. 